Portland State University

PDXScholar

4-1-1993

\title{
Temperature dependence of optical properties for amorphous silicon at wavelengths of 632.8 and 752 $\mathrm{nm}$
}

P.T. Leung

Portland State University

Nhan Do

Oguz Yavas

Andrew C. Tam

Wing P. Leung

See next page for additional authors

Follow this and additional works at: https://pdxscholar.library.pdx.edu/phy_fac

Part of the Physics Commons

Let us know how access to this document benefits you.

\section{Citation Details}

Yavas, O., Do, N., Tam, A., Leung, P., Leung, W., Park, H., \& ... Leiderer, P. (1993). Temperature dependence of optical properties for amorphous silicon at wavelengths of 632.8 and $752 \mathrm{~nm}$. Optics Letters, 18(7), 540-542.

This Article is brought to you for free and open access. It has been accepted for inclusion in Physics Faculty Publications and Presentations by an authorized administrator of PDXScholar. Please contact us if we can make this document more accessible: pdxscholar@pdx.edu. 


\section{Authors}

P.T. Leung, Nhan Do, Oguz Yavas, Andrew C. Tam, Wing P. Leung, Hee K. Park, Costas P. Grigoropoulos, Johannes Boneberg, and Paul Leiderer 


\title{
Temperature dependence of optical properties for amorphous silicon at wavelengths of 632.8 and $752 \mathrm{~nm}$
}

\author{
Oguz Yavas, ${ }^{*}$ Nhan Do, ${ }^{\dagger}$ Andrew C. Tam, P. T. Leung, ${ }^{\ddagger}$ Wing P. Leung, Hee K. Park, ${ }^{\S}$ \\ Costas P. Grigoropoulos, ${ }^{\S}$ Johannes Boneberg, ${ }^{*}$ and Paul Leiderer* \\ IBM Research Division, Almaden Research Center, 650 Harry Road, San Jose, California 95120-6099
}

Received October 13, 1992

\begin{abstract}
The temperature dependence of the optical properties for amorphous silicon is studied at wavelengths of 632.8 and $752 \mathrm{~nm}$. Both the refractive index and extinction coefficient increase linearly with temperature for $752 \mathrm{~nm}$, while the refractive index decreases and the extinction coefficient increases for $632.8 \mathrm{~nm}$. The rate of increase of the extinction coefficient at $632.8 \mathrm{~nm}$ is twice as much as that for $752 \mathrm{~nm}$.
\end{abstract}

The temperature dependence of the optical properties of solids, especially crystalline silicon $(c-\mathrm{Si})$, has been the focus of many studies. ${ }^{1-3}$ This interest is partly motivated by the desire for better understanding of the laser-material interaction, such as laser annealing ${ }^{4}$ and laser-induced explosive evaporation of liquid films. ${ }^{5}$ Numerical simulations of laser annealing fit well to experimental observations, ${ }^{6,7}$ but it is often concluded that the temperature dependence of the optical properties of the material must be taken into account in order to achieve better agreement with experiments. ${ }^{8,9}$ Amorphous silicon $(a-\mathrm{Si})$, however, is less studied in this aspect. Although a great deal of room-temperature data are available ${ }^{10}$ only a few reports have been made on the studies of the temperature dependence of its optical constants at the Nd:YAG wavelength $(1064 \mathrm{~nm})$, which indicated almost no temperature dependence. ${ }^{11-13}$ Thus the optical constants for $a$-Si have been considered as constant with temperature. However, we reported recently that this assumption is not true at the wavelength of $752 \mathrm{~nm} .{ }^{14}$ At this wavelength with stronger optical absorption, we observed a significant increase of the optical constants for $a-\mathrm{Si}$ with temperature. Based on this observation we developed a new technique for the transient measurements of the temperature profile in thin $a$-Si films on fused-quartz substrates using the optical transmission probe at $752 \mathrm{~nm} .{ }^{16,16}$ This method has been successfully applied to our studies on the nucleation dynamics of the explosive evaporation of liquid films on $a$-Si samples irradiated by UV laser pulses and provided useful data. ${ }^{16,17}$

In a previous paper ${ }^{14}$ we pointed out that a larger temperature dependence of the optical constants for $a-\mathrm{Si}$ is possible in the stronger absorption regime. Therefore we extend here the investigations to shorter wavelengths, especially to the $\mathrm{He}-\mathrm{Ne}$ laser wavelength. This is also of practical importance, since the $\mathrm{He}-\mathrm{Ne}$ laser is the most widely available and the most commonly used laser for optical probing. Here we present the results of our comparative study at the wavelengths of 632.8 and $752 \mathrm{~nm}$. The temperature range of the measurements here is also broader compared with that in our previous research. ${ }^{14}$ As we expected, we observe a significant temperature dependence for $n(T)$ and $k(T)$ for $a$-Si also at the $\mathrm{He}-\mathrm{Ne}$ laser wavelength.

The $a$-Si samples for our experiment are $0.2 \mu \mathrm{m}$ thick and prepared in the same way as previously reported ${ }^{14}$ by e-beam evaporation of $c$-Si in vacuum $\left(10^{-7}\right.$ Torr) onto fused-quartz substrates $(250 \mu \mathrm{m}$ thick). The substrate temperature is kept at $140^{\circ} \mathrm{C}$, and the deposition rate is kept at $1 \mathrm{~nm} / \mathrm{s}$. The uniformity and accuracy of the film thickness is confirmed by using the Tencor Alpha-Step 200 surface profilometer. The samples are then annealed at a temperature of $380^{\circ} \mathrm{C}$ in a nitrogen chamber for $\sim 5 \mathrm{~h}$. Under these conditions the formation of oxide or nitride is kept at a minimum. ${ }^{18}$ The heat treatment results in stress relaxation of the samples and thus good reproducibility for the optical measurements (reflectance or transmittance versus change of temperature).

We have made use of the standard reflectance $(\mathscr{R})$ and transmittance $(\mathscr{T})$ measurements for the determination of $n(T)$ and $k(T)$ for $a-\mathrm{Si}^{19} \quad$ The sample is mounted on an aluminum block that can be heated from room temperature to $\sim 500^{\circ} \mathrm{C}$ by using a heater-thermocouple system. The laser beam is directed at an angle of $5^{\circ}$ to the normal of the sample. Both $\mathscr{R}$ and $\mathscr{T}$ signals are detected simultaneously by using photodetectors connected to an oscilloscope. Measurements were made both with increasing temperature from room temperature up to $475^{\circ} \mathrm{C}$ and with decreasing temperature from this peak temperature to detect any permanent change in the material properties that are due to the sample's being exposed to high temperatures during the measurement. We observed excellent agreement in both measurement modes, indicating that no changes occurred in the material properties at the highest temperature used. The results for $\mathscr{R}$ and $\mathscr{T}$ are shown in Figs. 1 and 2, respectively. Both the reflectivity and transmissivity change linearly with temperature for the two different wavelengths studied. The change of reflectivity with temperature is in the opposite direction for different wavelengths: it decreases with temperature for $632.8 \mathrm{~nm}$, while it increases for $752 \mathrm{~nm}$. In contrast to this observation for reflec- 


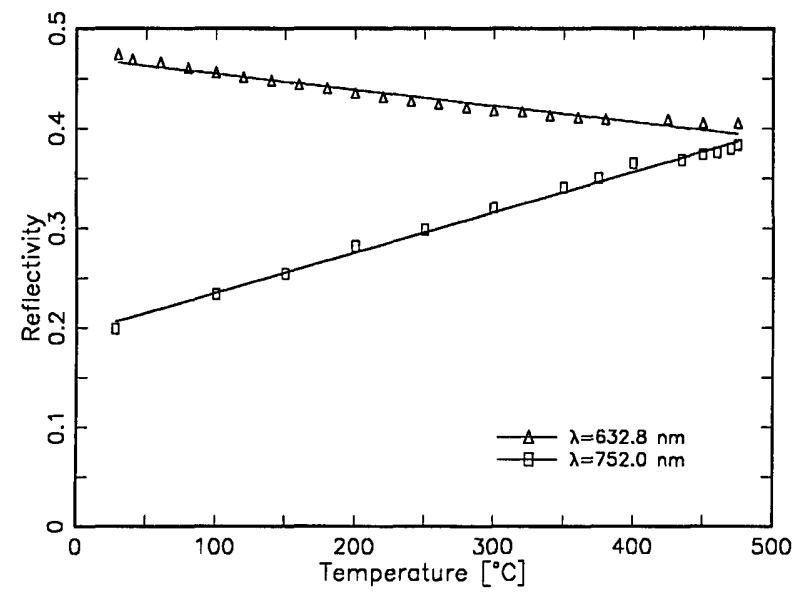

Fig. 1. Reflectivity as a function of temperature for the $a$-Si sample of thickness $0.2 \mu \mathrm{m}$.

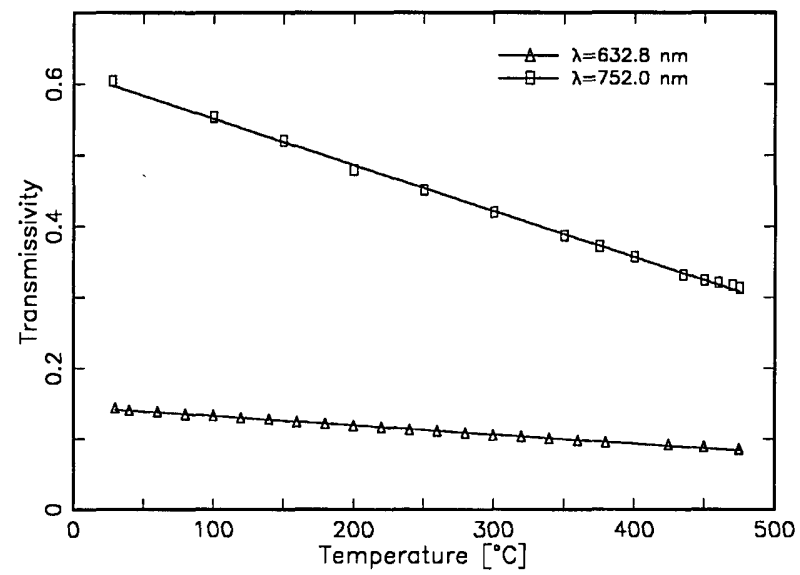

Fig. 2. Transmissivity as a function of temperature for the $a$-Si sample.

tivity, transmissivity decreases with temperature for both wavelengths. The rate of change of $\mathscr{R}$ and $\mathscr{T}$ with temperature is significantly different for the two wavelengths. In the temperature range from 20 to $475{ }^{\circ} \mathrm{C}$ the values of $\mathscr{R}$ and $\mathscr{T}$ change only approximately $17 \%$ for $632.8 \mathrm{~nm}$, but for $752 \mathrm{~nm}$ we observe that the change for $\mathscr{R}$ and $\mathscr{T}$ each amounts to $50 \%$. Thus, in comparison with that at $632.8 \mathrm{~nm}$, the probe wavelength of $752 \mathrm{~nm}$ is at least two times more sensitive to a temperature change of the $a-\mathrm{Si}$ sample.

The measured $\mathscr{R}(T)$ and $\mathscr{T}(T)$ values are then converted into $n(T)$ and $k(T)$ by using a computer iteration program that makes use of the Fresnel formula for a multilayer system. Also the thermal expansion of $a-\mathrm{Si}$ and fused quartz are taken into account in this fitting program, assuming the linear expansivity to be $3 \times 10^{-6}$ and $5 \times 10^{-7} \mathrm{C}^{-1}$ for $\alpha-\mathrm{Si}$ and fused quartz, respectively. The obtained results for $n(T)$ and $k(T)$ are shown in Figs. 3 and 4 . The above discussed results for $\mathscr{R}(T)$ and $\mathscr{T}(T)$ are reflected also in remarkable differences in the temperature dependence of $n(T)$ and $k(T)$ for the two different wavelengths. At the wavelength of $752 \mathrm{~nm}$ both the refractive index and the extinction coefficient increase linearly with temperature, in good agreement with our previous result. It turns out that the linear dependence of $n(T)$ and $k(T)$ on the temperature is still valid in the higher temperature range that we studied in the present research. At the $\mathrm{He}-\mathrm{Ne}$ laser wavelength of $632.8 \mathrm{~nm}$, however, we observe a totally different temperature dependence of the optical constants for $a$-Si. The refractive index decreases with temperature linearly, but the extinction coefficient increases, with an increasing rate of approximately two times higher than that at $752 \mathrm{~nm}$. The obtained data can be fitted by the following linear equations:

$$
\begin{aligned}
& n(T)=4.19-1.43 \times 10^{-4} T, \\
& k(T)=0.24+4.85 \times 10^{-4} T \quad \text { at } \lambda=632.8 \mathrm{~nm}, \\
& n(T)=3.92+2.71 \times 10^{-4} T, \\
& k(T)=2.59 \times 10^{-2}+2.25 \times 10^{-4} \mathrm{~T}
\end{aligned}
$$$$
\text { at } \lambda=752 \mathrm{~nm} \text {, }
$$

where $T$ is expressed in degrees celsius. The fact that the refractive index decreases with temperature for $632.8 \mathrm{~nm}$ but increases for $752 \mathrm{~nm}$ is in sharp contrast to the case for $c$-Si. It is reported that refractive index of $c$-Si increases with temperature at

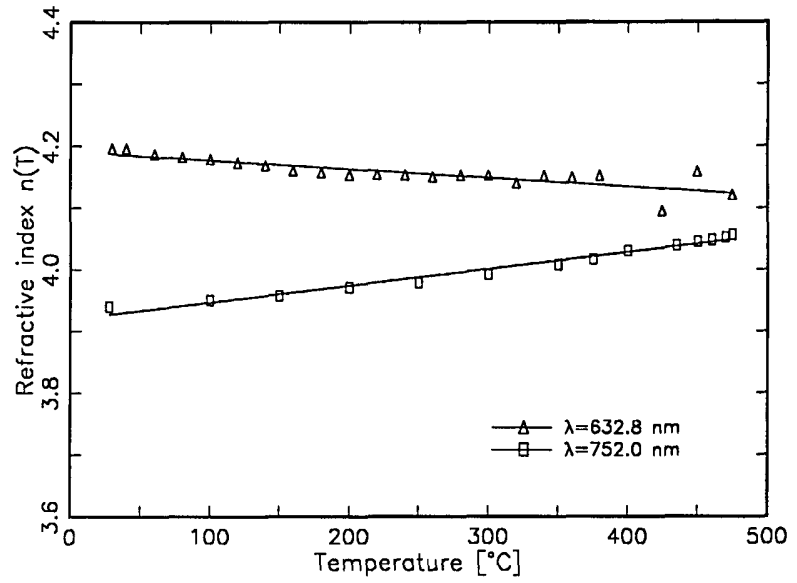

Fig. 3. Refractive index as a function of temperature for the $a$-Si sample.

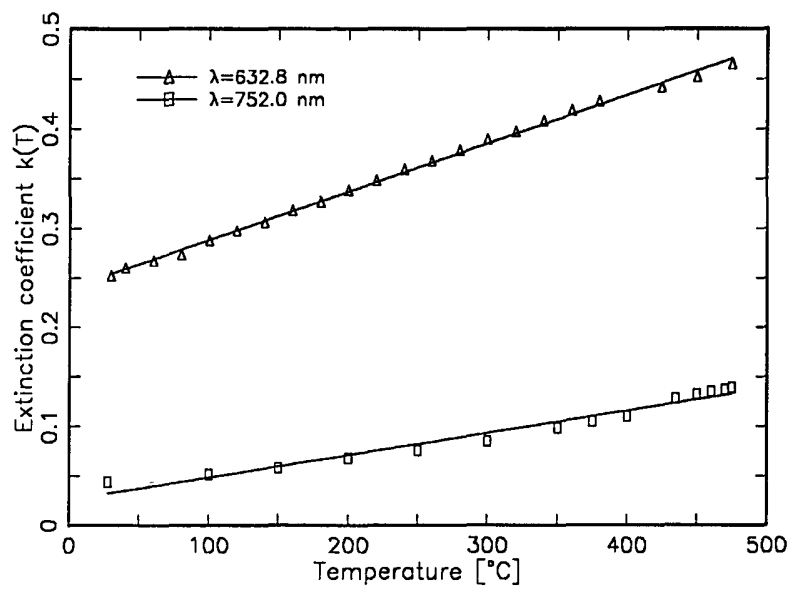

Fig. 4. Extinction coefficient as a function of temperature for the $a$-Si sample. 
a higher rate for shorter wavelengths. ${ }^{20}$ In general, we expect the following behavior for $\mathrm{d} n / \mathrm{d} T$ :

$$
\begin{aligned}
\mathrm{d} n / \mathrm{d} T= & \mathrm{d} n / \mathrm{d} T \text { (volume effect) } \\
& +\mathrm{d} n / \mathrm{d} T \text { (electronic effect) },
\end{aligned}
$$

where volume effect refers to thermal expansion and always causes a decrease of $n$ with temperature. Our results imply that this volume effect is more predominant in the $a$-Si case compared with that in the $c$-Si case. The results for the extinction coefficient $k$, however, are consistent with the trend in the case of $c$-Si. It is observed that $k$ of $c$-Si increases both with temperature and photon energy as long as the photon energy is below the direct band gap $(3.4 \mathrm{eV}){ }^{21}$ Even though the rate of change of $k$ with temperature for $a-\mathrm{Si}$ at $632.8 \mathrm{~nm}$ is two times higher than that at $752 \mathrm{~nm}$, the variation of $\mathscr{R}$ and $\mathscr{T}$ with temperature for $632.8 \mathrm{~nm}$ is less than that for $752 \mathrm{~nm}$ owing to the decrease of $n$.

In conclusion, we have observed a linear dependence of $n(T)$ and $k(T)$ with temperature from 20 to $475{ }^{\circ} \mathrm{C}$ for $752 \mathrm{~nm}$. In addition, we experimentally verify that the optical constants for $a$-Si have a strong linear dependence on temperature also at $632.8 \mathrm{~nm}$. We have observed that the temperature and wavelength dependence of $k$ are consistent with the trend in the case of $c-\mathrm{Si}$, whereas the result for $n$ differs significantly from that for $c-\mathrm{Si}$. We are aware of the fact that the properties of $a-\mathrm{Si}$ may depend significantly on the fabrication process; however, if the $a$-Si sample is prepared under the same conditions, then the optical constants obtained here are reproducible, as we have verified.

Oguz Yavas acknowledges financial support from the Friedrich-Ebert-Stiftung, Bonn, Germany.

*Permanent address, Department of Physics, University of Konstanz, D-7750 Konstanz, Germany.

${ }^{+}$Present address, Department of Physics, University of California, Irvine, Irvine, California 92717.

${ }^{\ddagger}$ Present address, Department of Physics, Portland State University, Portland, Oregon 97207-0751.

${ }^{\S}$ Permanent address, Department of Mechanical Engineering, University of California, Berkeley, Berkeley, California 94720.

\section{References}

1. See, e.g., H. G. Dreehsen, C. Hartwich, J. H. Schaefer, and J. Uhlenbusch, J. Appl. Phys. 56, 238 (1984).
2. See, e.g., G. E. Jellison, Jr., and F. A. Modine, Rep. ORNL/TM-9718 (Oak Ridge National Laboratory, Oak Ridge, Tenn., 1985); G. E. Jellison, Jr., and D. H. Lowndes, Appl. Phys. Lett. 51, 352 (1987); M. Bertolotti, V. Bogdanov, A. Ferrari, A. Jascow, N. Nazorova, A. Pikhtin, and L. Schirone, J. Opt. Soc. Am. B 7, 918 (1990).

3. See, e.g., M. E. Thomas, in Handbook of Optical Constants of Solids II, E. D. Palik, ed. (Academic, New York, 1991), p. 177 and references therein.

4. R. F. Wood, C. W. White, and R. T. Young, eds., Semiconductors and Semimetals (Academic, New York, 1984).

5. W. Zapka, W. Ziemlich, and A. C. Tam, Appl. Phys. Lett. 58, 2217 (1991).

6. C. K. Ong, H. S. Tan, and E. H. Sin, Mater. Sci. Eng. 79, 79 (1986).

7. I. Lukes, R. Sasik, and R. Cerny, Appl. Phys. A 54, 327 (1992).

8. J. Boneberg, O. Yavas, B. Mierswa, and P. Leiderer, Proc. Soc. Photo-Opt. Instrum. Eng. 1598, 84 (1991).

9. S. D Unamuno and E. Fogarassy, Appl. Surf. Sci. 36, 1 (1989).

10. See, e.g., H. Piller, in Handbook of Optical Constants of Solids I, E. D. Palik, ed. (Academic, New York, 1985), p. 571 and references therein.

11. M. R. T. Siregar, M. von Allmen, and W. Luthy, Helv. Phys. Acta 52, 45 (1979).

12. M. von Allmen, W. Luthy, J. P. Thomas, M. Fallavier, J. M. Mackowski, R. Kirsch, M.-A. Nicolet, and M. E. Roulet, Appl. Phys. Lett. 34, 82 (1979).

13. J. M. Liu, Ph.D. dissertation (Harvard University, Cambridge, Mass., 1982).

14. N. Do, L. Klees, P. T. Leung, F. Tong, W. P. Leung, and A. C. Tam, Appl. Phys. Lett. 60, 2186 (1992).

15. H. K. Park, X. Xu, C. P. Grigoropoulos, N. Do, L. Klees, P. T. Leung, and A. C. Tam, Appl. Phys. Lett. 61, 749 (1992).

16. P. T. Leung, N. Do, L. Klees, W. P. Leung, F. Tong, L. Lam, W. Zapka, and A. C. Tam, J. Appl. Phys. 72, 2256 (1992).

17. L. Klees, P. T. Leung, N. Do, F. Tong, W. P. Leung, and A. C. Tam, in Conference on Lasers and Electro-Optics, Vol. 12 of 1992 OSA Technical Digest Series (Optical Society of America, Washington, D.C., 1992), p. 502.

18. The nitridation of Si occurs at a much higher temperature. See, e.g., H. Nakamura, M. Kaneko, and S. Matsumoto, Appl. Phys. Lett. 43, 691 (1983).

19. J. E. Fredrickson, C. N. Waddell, W. G. Spitzer, and G. K. Hubler, Appl. Phys. Lett. 40, 172 (1982).

20. G. E. Jellison, Jr., and H. H. Burke, J. Appl. Phys. 60, 841 (1986).

21. G. E. Jellison, Jr., and F. A. Modine, Appl. Phys. Lett. 41, 180 (1982). 